\title{
Pharmacological Sequestration of Mitochondrial Calcium Uptake Protects Neurons Against Glutamate Excitotoxicity
}

\author{
Plamena R. Angelova ${ }^{1}$ - Darya Vinogradova ${ }^{2} \cdot$ Margarita E. Neganova ${ }^{2} \cdot$ Tatiana P. Serkova $^{2} \cdot$ Vladimir V. Sokolov $^{2} \cdot$ \\ Sergey O. Bachurin ${ }^{2}$ • Elena F. Shevtsova ${ }^{2} \cdot$ Andrey Y. Abramov $^{1}$ (D)
}

Received: 17 April 2018 / Accepted: 26 June 2018 / Published online: 14 July 2018

(C) The Author(s) 2018

\begin{abstract}
Neuronal excitotoxicity which is induced by exposure to excessive extracellular glutamate is shown to be involved in neuronal cell death in acute brain injury and a number of neurological diseases. High concentration of glutamate induces calcium deregulation which results in mitochondrial calcium overload and mitochondrial depolarization that triggers the mechanism of cell death. Inhibition of mitochondrial calcium uptake could be potentially neuroprotective but complete inhibition of mitochondrial calcium uniporter could result in the loss of some physiological processes linked to $\mathrm{Ca}^{2+}$ in mitochondria. Here, we found that a novel compound, TG-2112x, can inhibit only the lower concentrations mitochondrial calcium uptake (induced by $100 \mathrm{nM}$ $5 \mu \mathrm{M})$ but not the uptake induced by higher concentrations of calcium $(10 \mu \mathrm{M}$ and higher). This effect was not associated with changes in mitochondrial membrane potential and cellular respiration. However, a pre-treatment of neurons with TG-2112x protected the neurons against calcium overload upon application of toxic concentrations of glutamate. Thus, sequestration of mitochondrial calcium uptake protected the neurons against glutamate-induced mitochondrial depolarization and cell death. In our hands, TG-2112x was also protective against ionomycin-induced cell death. Hence, low rate mitochondrial calcium uptake plays an underestimated role in mitochondrial function, and its inhibition could protect neurons against calcium overload and cell death in glutamate excitotoxicity.
\end{abstract}

Keywords Mitochondria $\cdot$ Calcium $\cdot$ Glutamate $\cdot$ Excitotoxicity $\cdot$ Neuron $\cdot$ Glutamate

$\begin{array}{ll}\text { Abbreviations } \\ \text { ER } & \text { Endoplasmic reticulum } \\ \text { MCU } & \text { Mitochondrial Ca2+ uniporter } \\ \text { CGC } & \text { Cerebellar granule cells } \\ \text { HBSS } & \text { HEPES-buffered salt solution } \\ \Delta \psi \mathrm{m} & \text { Mitochondrial membrane potential } \\ \text { Rh123 } & \text { Rhodamine 123 } \\ \text { PI } & \text { Propidium iodide }\end{array}$

Plamena R. Angelova and Darya Vinogradova contributed equally to this work.

Elena F. Shevtsova shevtsova@ipac.ac.ru

Andrey Y. Abramov a.abramov@ucl.ac.uk

1 Department of Molecular Neuroscience, UCL Institute of Neurology, Queen Square, London WC1N 3BG, UK

2 Institute of Physiologically Active Compounds Russian Academy of Sciences, Chernogolovka 142432, Russia
OCR Oxygen consumption rates

ECAR Extracellular acidification rates

CRC Calcium retention capacity

\section{Introduction}

Glutamate is one of the major neurotransmitters in the brain. A number of conditions, which lead to exposure of neurons to excessive concentrations of glutamate, induce excitotoxic cell death [1]. Glutamate excitotoxicity is suggested to be a primary mechanism of acute brain injury, including brain trauma and stroke. Although there is a number of compounds shown to be protective against glutamate toxicity on primary neurons in culture, clinical trials data demonstrated unsatisfactory results for drugs designed to treat conditions incited by excitotoxicity [2].

Activation of glutamate receptors induces calcium influx into the cytosol of neurons where it is buffered by mitochondria. Calcium ATPases and ion exchangers on the plasma or ER membrane transport calcium out of the cytosol and restore 
basal calcium concentrations. Under pathological conditions, high concentration of glutamate induces delayed calcium deregulation and profound mitochondrial depolarization which is shown to be the trigger for neuronal cell death $[3,4]$. Mitochondrial depolarization is calcium-dependent and can be prevented by specific inhibition of mitochondrial calcium uptake [5].

Mitochondria uptake calcium via specific electrogenic carrier named mitochondrial $\mathrm{Ca}^{2+}$ uniporter (MCU) [6]. Knockout of MCU is shown to be protective against excitotoxicity induced by NMDA [7]. Despite the recent developments of molecular tools to identify the molecular determinants of MCU, it is difficult to estimate the role of glutamate-induced mitochondrial depolarization and cell death for a number of reasons. On one side, Ruthenium Red and its active component Ru360, which have been used for inhibition of MCU for many years, specifically inhibit mitochondrial calcium uptake only in isolated mitochondria. However, Ruthenium Red is almost impermeable for cells and inhibits a large number of plasmalemmal ion channels; Ru360 is oxidizing fast and on a cellular level can be successfully used only for short-term experiments. On the other hand, mitochondrial calcium uptake can be restricted by mitochondrial depolarization [8], but it can induce bioenergetic failure that is enhancing the glutamate toxicity [9-12].

Here, we demonstrate that our newly synthesized compound TG-2112x protects neurons against calcium overload toxicity in the presence of ionomycin and against glutamate excitotoxicity by inhibition of glutamate-induced mitochondrial depolarization. The effect of TG-2112x on the mitochondrial membrane potential could be mainly explained by the limitation of mitochondrial calcium uptake by this compound. However, TG-2112x successfully inhibits mitochondrial calcium uptake induced only by low calcium concentration but it could not block $\mathrm{Ca}^{2+}$ influx induced by higher concentrations of calcium in the same way as RU360. We therefore suggest that TG-2112× can only partially inhibit MCU or, that is more likely, to block MCU-independent mitochondrial calcium uptake. Here, we find an importance of low calcium uptake in glutamate-induced mitochondrial depolarization and in the mechanism of cell death induced by excitotoxicity.

\section{Materials and Methods}

\section{Cell Culture}

Co-cultures of cortical or hippocampal neurons and astrocytes were prepared as described previously $[13,14]$ with modifications, from Sprague-Dawley rat pups 2-4 days post-partum (UCL breeding colony). Brain cortices or hippocampi were removed into ice-cold HBSS $\left(\mathrm{Ca}^{2+}, \mathrm{Mg}^{2+}\right.$-free, Invitrogen, Paisley, UK). The tissue was minced and trypsinized $(0.1 \%$ for $15 \mathrm{~min}$ at $37^{\circ} \mathrm{C}$ ), triturated and plated on poly-D-lysinecoated coverslips, and cultured in Neurobasal medium (Gibco-Invitrogen, Paisley, UK) supplemented with B-27 (Gibco-Invitrogen, Paisley, UK) and $2 \mathrm{mM}$ L-glutamine. The cultures were maintained at $37{ }^{\circ} \mathrm{C}\left(5 \% \mathrm{CO}_{2}\right)$ and the media changed twice a week. Cells were used at 12-15 days in vitro.

Cerebellar granule cells (CGC) were prepared from the postnatal rats (7-8 days old, no sex separation) by the following procedure based on the generally accepted methods [8]. The pieces of cerebellum were digested with $0.25 \mathrm{mg} / \mathrm{ml}$ tryp$\sin$ for $20 \mathrm{~min}$ at $37^{\circ} \mathrm{C}$. After washing, cells were dissociated by triturating. Following filtration through the nylon mesh, the cells were plated at a density of $2.5-5 \times 10$ cells per $\mathrm{ml}$ on poly(ethyleneimine)-coated 96-well plates (Corning) and maintained at $37{ }^{\circ} \mathrm{C}$ in a humidified incubator with $5 \% \mathrm{CO}_{2} /$ 95\% room air. The medium was composed of Eagle's minimum essential medium: Dulbecco's Modified Eagle's Medium (Gibco)/Nutrient F-12 (Gibco) Ham 1:1 and fetal calf serum (10\%) supplemented with $20 \mathrm{mM}$ potassium chloride, $10 \mathrm{mM}$ glucose, $2 \mathrm{mM}$ glutamine, and $50 \mathrm{mg} / \mathrm{ml}$ gentamycin sulfate. Cytosine arabinoside $(20 \mu \mathrm{g} / \mathrm{ml})$ was added $24-48 \mathrm{~h}$ later to prevent the replication of non-neuronal cells.

\section{Imaging $\left[\mathrm{Ca}^{2+}\right]_{\mathrm{c}}$ and Mitochondrial Membrane Potential}

Hippocampal or cortical neurons were loaded for $30 \mathrm{~min}$ at room temperature with $5 \mu \mathrm{M}$ fura-ff AM (Molecular probes) or $5 \mu \mathrm{M}$ fura- $2 \mathrm{AM}$ (molecular probes) and $0.005 \%$ Pluronic in a HEPES-buffered salt solution (HBSS). For simultaneous measurement of $\left[\mathrm{Ca}^{2+}\right]_{\mathrm{c}}$ and mitochondrial membrane potential $\left(\Delta \Psi_{\mathrm{m}}\right), \operatorname{Rh} 123(1 \mu \mathrm{M}$, Molecular Probes) was added into the cultures during the last $15 \mathrm{~min}$ of the fura- 2 or fura-ff loading period, and the cells were then washed 3-5 times before experiment.

Fluorescence measurements were obtained on an epifluorescence inverted microscope equipped with a $\times 20$ fluorite objective. $\left[\mathrm{Ca}^{2+}\right]_{\mathrm{i}}$ and $\Delta \psi_{\mathrm{m}}$ were monitored in single cells using excitation light provided by a Xenon arc lamp, the beam passing sequentially through $10-\mathrm{nm}$ band pass filters centered at 340, 380, and $490 \mathrm{~nm}$ housed in computercontrolled filter wheel (Cairn Research, Kent, UK). Emitted fluorescence light was reflected through a 515-nm long-pass filter to a cooled CCD camera (Retiga, QImaging, Canada). All imaging data were collected and analyzed using software from Andor (Belfast, UK). The fura-2 or fura-ff data have not been calibrated in terms of $\left[\mathrm{Ca}^{2+}\right]_{i}$ because of the uncertainty arising from the use of different calibration techniques. We have normalized the signals between resting level (set to 0 ) and a maximal signal (which correspond to full mitochondrial depolarization) generated in response to the protonophore FCCP $(1 \mu \mathrm{M}$; set to $100 \%)$. 


\section{Imaging of Mitochondrial Calcium}

Confocal images were obtained using a Zeiss 710 CLSM using a $\times 40$ oil immersion objective. The 488 -nm Argon laser line was used to excite mitoGCaMP6f fluorescence which was measured at 505-550 $\mathrm{nm}$. For Rhod-5 $\mathrm{N}$ measurements, the $563 \mathrm{~nm}$ excitation and 580-630 $\mathrm{nm}$ emission were used. All data presented were obtained from at least five coverslips and 2-3 different cell culture preparations.

\section{NADH and FAD Measurements}

NADH autofluorescence was monitored using an epifluorescence inverted microscope equipped with a $\times 40$ fluorite objective. Excitation light $(350 \mathrm{~nm})$ was provided by a Xenon arc lamp, the beam passing through a monochromator (Cairn Research, Kent, UK). Emitted fluorescence light was reflected through a 455-nm long-pass filter to a cooled CCD camera (Retiga, QImaging, Canada). Imaging data were collected and analyzed using software from Andor (Belfast, UK). FAD++ autofluorescence was monitored using a Zeiss 710 VIS CLSM and $\mathrm{a} \times 40$ objective. We used 454-nm laser for excitation with emission at $505-550 \mathrm{~nm}$.

\section{Neuronal Toxicity Experiment}

Cells were incubated with propidium iodide (PI; $20 \mu \mathrm{M}$ ) and Hoechst 33342 (4.5 $\mu \mathrm{M}$; Molecular Probes, Eugene, OR). Viable cells exclude the red fluorescent PI (which can penetrate only in permeabilized cells) whereas Hoechst stains chromatin blue in all cells thus allowing dead cells to be quantified.

\section{Rat Brain Mitochondria Isolation}

Rat brain non-synaptosomal mitochondria were isolated from Wistar strain male rats aged 3.5-4 months old (250-350 g), as previously described in [15]. Briefly, according to the regulations, the rats were anesthetized by carbon dioxide and killed by decapitation. The brain was quickly removed and homogenized in an ice-cold isolation buffer (IB), $\mathrm{pH}$ 7.4: $75 \mathrm{mM}$ sucrose, $225 \mathrm{mM}$ mannitol, $10 \mathrm{mM}$ K-HEPES with addition of $0.5 \mathrm{mM}$ EGTA, $0.5 \mathrm{mM}$ EDTA, and $1 \mathrm{mg} / \mathrm{ml} \mathrm{BSA}$. The homogenate was centrifuged for $11 \mathrm{~min}$ at $1500 \times \mathrm{g}$. The pellet was homogenized in half the volume of the same buffer and centrifugation was repeated. The combined supernatants were centrifuged at $10500 \times \mathrm{g}$ for $11 \mathrm{~min}$. The resulting pellet was resuspended in $12 \%$ Percoll, layered to Percoll gradient (40$23-12 \%$ ) and centrifuged at $30700 \times g$ at $4{ }^{\circ} \mathrm{C}$ for $15 \mathrm{~min}$. The mitochondrial layer was collected and washed twice using centrifugation. The final pellet was re-suspended in the IB containing 0.02 mM EGTA.
The mitochondrial protein concentration was determined using a Biuret method with bovine serum albumin as a standard.

\section{Mitochondrial Permeability Transition}

$\mathrm{Ca}^{2+}$-induced cyclosporine A-sensitive mitochondrial swelling was used to study the mitochondrial permeability transition. The mitochondrial swelling was determined by monitoring the absorbance at $620 \mathrm{~nm}$ using a Victor 3 multi-well fluorescence plate reader (Perkin Elmer, Germany). The nonsynaptosomal brain mitochondria $(0.2 \mathrm{mg} / \mathrm{mL})$ were incubated in a buffer, containing $75 \mathrm{mM}$ sucrose, $225 \mathrm{mM}$ mannitol, 10 mM K-HEPES (pH 7.4), 0.02 mM EGTA, $1 \mathrm{mM} \mathrm{KH}_{2} \mathrm{PO}_{4}$, $5 \mathrm{mM}$ succinate, and $0,5 \mathrm{M}$ rotenone. Compound or equal volumes of vehicle were added to mitochondria suspensions, and after $5 \mathrm{~min}$, the mitochondrial permeability transition is induced by the $25 \mu \mathrm{M} \mathrm{CaCl}_{2}$ additions. The maximum swelling rate was calculated and normalized between rate of spontaneous swelling and maximum rate of $\mathrm{CaCl}_{2}$-induced swelling of control probe.

\section{Calcium Retention Capacity}

Calcium accumulation and retention capacity was evaluated in the KCl-based medium supplemented with $100 \mathrm{nM}$ Calcium Green-5 N (Molecular Probes) using a Victor3 multi-well fluorescence plate reader (Perkin Elmer, Germany) with ex/ $\mathrm{em}=506 / 535 \mathrm{~nm}$. The brain mitochondria $(0.2 \mathrm{mg} / \mathrm{mL})$ were suspended in the KCl-based medium $(120 \mathrm{mM} \mathrm{KCl}, 20 \mathrm{mM}$ HEPES, $100 \mathrm{mM}$ sucrose, $0.2 \mathrm{mM} \mathrm{KH_{2 }} \mathrm{PO}_{4}, 0.45 \mathrm{mM}$ $\mathrm{MgCl}_{2}, \mathrm{pH}$ 7.2), containing substrates of respiratory chain (5 $\mathrm{mM}$ succinate with complex I inhibitor $1 \mu \mathrm{M}$ rotenone, $5 \mathrm{mM}$ glutamate/malate or $5 \mathrm{mM}$ pyruvate/malate), $0.15 \mathrm{mM}$ ADP, and $1 \mu \mathrm{g} / \mathrm{mL}$ oligomycin. All experiments were carried out in 96 -well plates at $30^{\circ} \mathrm{C}$. The "Bolus mode" of calcium addition was used [15].

All experiments were replicated in at least three separate mitochondrial preparations. All figures are representative of at least four separate independent experiments.

\section{Seahorse Extracellular Flux Assay}

Co-cultures of cortical neurons and glial cells were cultured on XF96 plates (Seahorse Bioscience-Agilent) at a density of 30,000-40,000 cells/well in neurobasal medium supplemented with $\mathrm{B} 27$, glutamine, glucose, and $\mathrm{NaCl}$ for 7-9 days. On the day of the assay, the cell culture medium was replaced with $150 \mu \mathrm{L} /$ well of pre-warmed low-buffered medium (DMEM base medium supplemented with $25 \mathrm{mM}$ glucose, $1 \mathrm{mM}$ sodium pyruvate, $31 \mathrm{mM} \mathrm{NaCl}, 2 \mathrm{mM}$ glutamine, $\mathrm{pH}$ 7.4) and the cells incubated at $37^{\circ} \mathrm{C}$ for $30 \mathrm{~min}$ in a non- $\mathrm{CO} 2$ incubator. TG-2112x was prepared in DMSO and then diluted to the 
appropriate concentrations in the low-buffered medium. Oxygen consumption rates (OCR) and extracellular acidification rates (ECAR) of the neurons were measured at $37{ }^{\circ} \mathrm{C}$ using a Seahorse XF96 Extracellular Flux Analyzer (Seahorse Bioscience-Agilent; equipment of Center for Collective Use IPAC RAS - agreement N14.621.21.0008, ID RFMEFI62114X0008). Three baseline measurements of OCR were taken before injection of different concentrations of TG-2112x. Three readings were taken after each addition: different concentrations of TG-2112x, oligomycin $(3 \mu \mathrm{M})$, FCCP $(3 \mu \mathrm{M})$, rotenone $(1 \mu \mathrm{M})$ with antimycin $(1 \mu \mathrm{M})$. Basal OCR and changes in OCR upon addition of the mitochondrial modulators were recorded and calculated by the XF96 software.

\section{Effect of TG-2112x on Ionomycin-Induced Toxicity}

The 8-10 days CGC cells were incubated with a TG-2112x or an equal volume of the solvent $(<1 \%$ of the volume) and $3 \mu \mathrm{M}$ ionomycin for $24 \mathrm{~h}$. The cell viability was assessed as the dehydrogenase activity with the 3-(4,5-dimethylthiazol-2yl)-2,5-diphenyltetrazolium bromide (MTT) assay. The measurements of absorbance were done using a Victor microplate reader (Perkin Elmer) at $570 \mathrm{~nm}$.

No blinding was performed for all experiments.

\section{Statistical and Data Analysis}

Statistical analysis and data analysis were performed using Origin 9 (Microcal Software Inc., Northampton, MA) software. Data was assessed for normality using the ShapiroWilk test. Statistical analysis was performed using unpaired two-tailed Student's $t$ test to analyze differences between two groups. A test for outliers was not conducted on the data. Results are expressed as means \pm standard error of the mean (S.E.M.). Differences were considered to be significantly different if $p<0.05$.

\section{Results}

\section{Synthesis of TG-2112x}

We synthesized our novel compound combining in one molecule two pharmacophore moieties of specific ligands whose biological targets are known to be involved in Alzheimer's disease pathogenesis. In the assembly of hybrid polyfunctional molecules, we used aminoadamantane derivatives as the first pharmacophore and tetrahydrocarbazole derivatives as the second pharmacophore. In recent years, promising compounds for the design of disease-modifying drugs for the therapy of neurodegenerative diseases have been found among carbazole derivatives. In particular, these are aminotetrahydrocarbazoles that are able to stimulate neurogenesis and to stabilize the endoplasmic reticulum (ER) calcium homeostasis by attenuating the FAD-PS1mediated exaggerated ER calcium release; they can improve the mitochondrial function measured by increased mitochondrial membrane potential and lower the $\mathrm{A} \beta$ peptide production by decreasing the cleavage of amyloid precursor protein (APP) by $\beta$-secretase, without notably affecting $\alpha$ - and $\gamma$ secretase cleavage activities. As a result of primary screening, the hit-compounds were revealed, which possess the properties of microtubules stabilizer, inhibitor of butyrylcholinesterase, and NMDA-receptors, and also prevent the calciuminduced mitochondrial swelling and protect the neuroblastoma SH-SY5Y against calcium overload [16]. Here, we study the possible mechanism of cytoprotective and mitoprotective effect of compound-leader TG-2112x (Fig.1).

\section{TG-2112x Protects Neurons Against Glutamate-Induced Mitochondrial Depolarization}

In agreement with previously published data, we show that application of $100 \mu \mathrm{M}$ glutamate to mature $(\geq 12$ days in vitro) hippocampal neurons induce an initial transient rise in $\left[\mathrm{Ca}^{2+}\right]_{\mathrm{c}}$ followed after a several minutes by a delayed increase to a plateau (Fig. 2a) [4, 5, 17]. Simultaneous measurements of calcium and mitochondrial potential showed that the delayed secondary increase in $\left[\mathrm{Ca}^{2+}\right]_{\mathrm{c}}$ is accompanied by a progressive and possibly complete loss of mitochondrial membrane potential (Fig. 2a, c). Pre-incubation of the cells with 0.5-1 $\mu \mathrm{M}$ TG-2112x did not change effect of $100 \mu \mathrm{M}$ glutamate on primary or delayed increase of $\left[\mathrm{Ca}^{2+}\right]_{\mathrm{c}}$ of cortical neurons (Fig. 2b, c). However, in the majority of neurons,

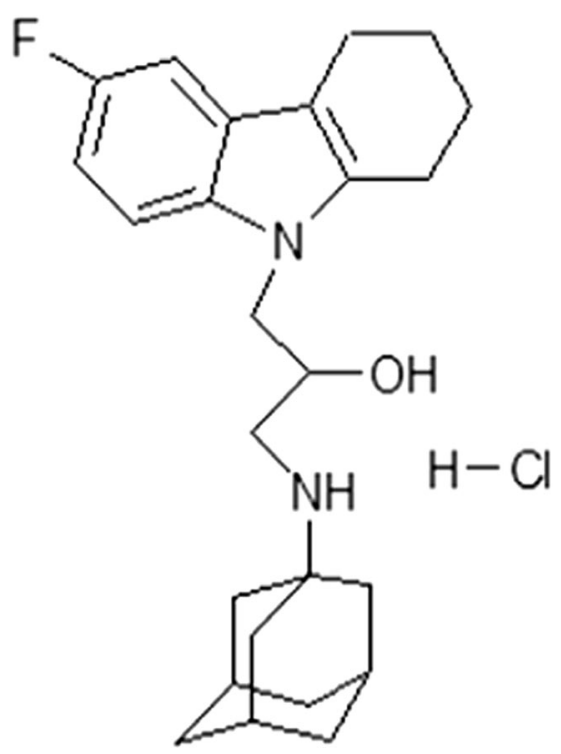

Fig. 1 Structure of the compound TG-2112x 
Fig. 2 Effect of TG-2112x on $\left[\mathrm{Ca}^{2+}\right]_{\mathrm{c}}$ and mitochondrial membrane potential during $100 \mu \mathrm{M}$ glutamate exposure. Simultaneous measurements of the changes in $\left[\mathrm{Ca}^{2+}\right]_{\mathrm{c}}$ (Fura-ff ratio) and $\Delta \psi_{\mathrm{m}}$ (relative $\mathrm{Rh} 123$ fluorescence) were made from single neurons. An increase in the Rh123 fluorescence reflects mitochondrial depolarization which corresponds to the effect of mitochondrial uncoupler FCCP $(1 \mu \mathrm{M})$ which was applied at the end of this and subsequent experiments to reflect complete dissipation of $\Delta \psi_{\mathrm{m}} . \mathbf{a}, \mathbf{b}$. illustration of the differences in the dynamics of $\left[\mathrm{Ca}^{2+}\right]_{\mathrm{c}}$ and $\Delta \psi_{\mathrm{m}}$ in control (a) and in response to pre-incubation of the cells with $0.5 \mu \mathrm{M}$ TG-2112x (b). c

Summaries of the effects of the different concentration of TG$2112 \mathrm{x}$ on glutamate-induced mitochondrial depolarization $(n=$ 88 neurons for control and 67,59 , and 89 cells for $0.5,1$, and $5 \mu \mathrm{M}$ TG-2112x). ** $p<0.001$
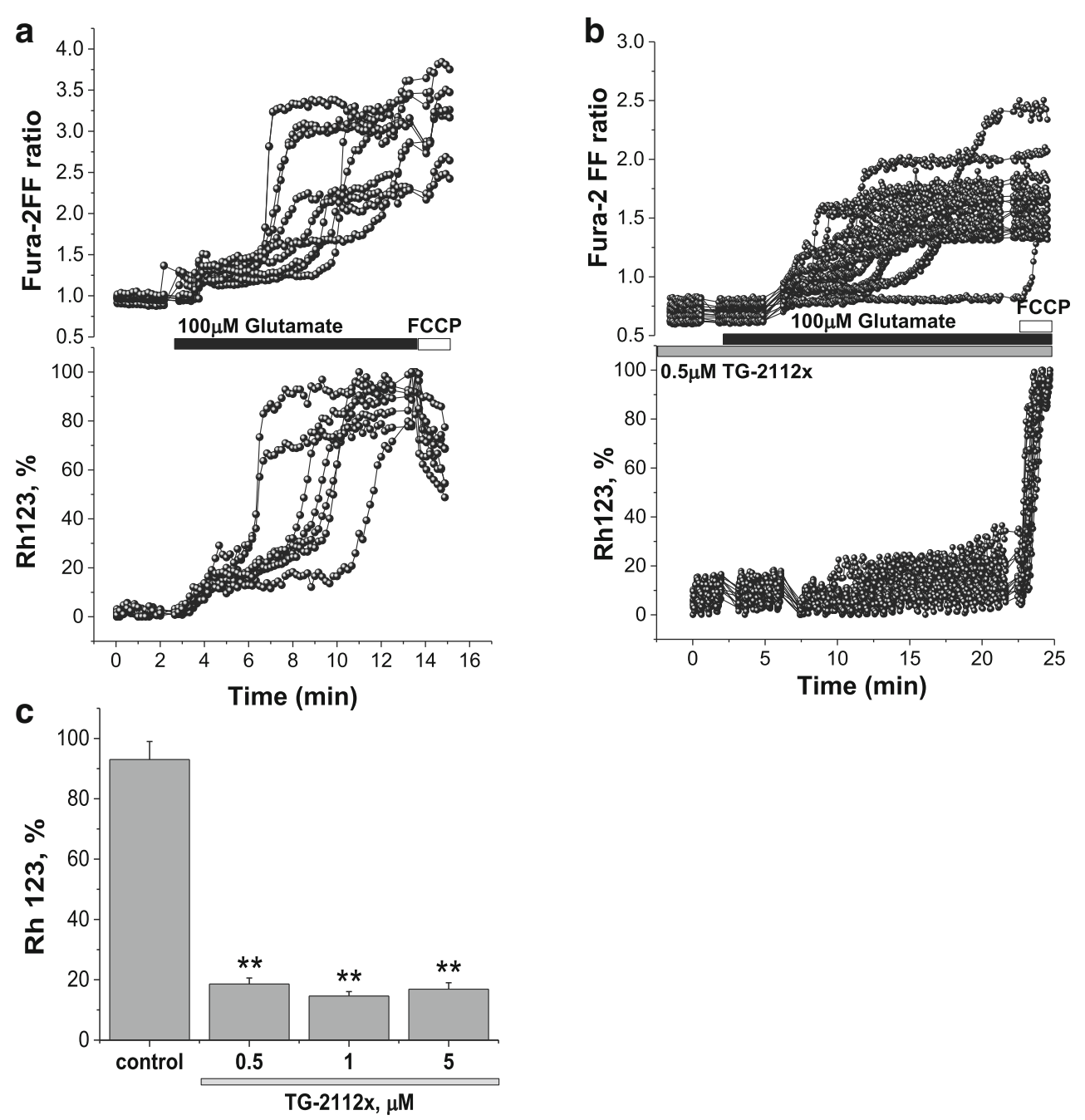

delayed calcium deregulation did not induce changes in $\Delta \psi \mathrm{m}$ ( $n=67$ out 88 neurons); in the rest of the cells, $100 \mu \mathrm{M}$ glutamate induced only minor depolarization (from $93 \pm 6 \%$ of Rh123 signal in control to $18.6 \pm 2$ in TG-2112 $(0.5 \mu \mathrm{M})$ treated cells; $p<0.001$; Fig. $2 \mathrm{c})$. It has been accepted that the profound decrease of $\Delta \psi \mathrm{m}$ is dependent on $\mathrm{Ca}^{2+}$ influx, and this effect is abolished if glutamate is applied in the absence of extracellular $\mathrm{Ca}^{2+}$; moreover, it can be blocked specifically by inhibitor of mitochondrial calcium uniporter RU360 [5, 18]. Glutamate-induced neuronal loss requires mitochondrial calcium accumulation [18]. In order to test if TG$2112 x$ changes calcium influx to cytosol in response to activation of glutamate receptors, we used small physiological concentrations of glutamate $(5 \mu \mathrm{M})$ on the cortical coculture loaded with fura-2. Glutamate induces transient peak followed by a recovery of $\left[\mathrm{Ca}^{2+}\right]_{\mathrm{c}}$ (Fig. 3a). Importantly, preincubation $(5 \mathrm{~min})$ of the cells with 0.5 or $1 \mu \mathrm{M}$ TG-2112x significantly increased the $\left[\mathrm{Ca}^{2+}\right]_{\mathrm{c}}$ of neurons in response to glutamate (from $0.42 \pm 0.03(n=67$ cells) in control to $1.02 \pm$ $0.04(n=56$ cells; $p<0.001)$ and to $0.87 \pm 0.03(n=76$ cells; $p<0.001)$ for $0.5 \mu \mathrm{M}$ and $1 \mu \mathrm{M}$ TG-2112x; Fig. 3b, c, d).
Thus, TG-2112x increases neuronal calcium responce to physiological concentration of glutamate that can suggest inhibition of $\mathrm{Ca}^{2+}$ efflux or blocking buffering of calcium by mitochondria.

\section{TG-2112x Inhibits Glutamate-Induced Mitochondrial Calcium Uptake in Neurons}

In order to test the effect of TG-2112x on mitochondrial calcium transport at the time of application of toxic concentration of glutamate, we used low affinity calcium indicator rhod-5n, which is predominantly localized in mitochondria due to its negative charge. However, it is still present in the cytosol, that allows us to measure $\left[\mathrm{Ca}^{2+}\right]_{\mathrm{c}}$ changes, including the delayed calcium deregulation. Exposure of cortical neurons to $100 \mu \mathrm{M}$ glutamate induced delayed calcium deregulation which can be seen in the cell body of the neurons (Fig. 4ai, bi). Mitochondrial signal which has appeared in the cell body has become impossible to separate from the rest of the signal due to high $\left[\mathrm{Ca}^{2+}\right]_{\mathrm{c}}$ in the cytosol of the neuronal body (Fig. 4a, b; aii, bii). However, mitochondria stay distinguishable in 
Fig. 3 Effect of TG-2112 on $\left[\mathrm{Ca}^{2+}\right]_{\mathrm{c}}$ changes in neurons under application of physiological concentration of glutamate. Preincubation of cells with $0.5 \mu \mathrm{M}$ (b) or $1 \mu \mathrm{M}$ (c) TG-2112x increased the effect of $5 \mu \mathrm{M}$ glutamate on $\left[\mathrm{Ca}^{2+}\right]_{\mathrm{c}}$ neurons compare to control (a). c Summary of the effects of TG$2112 x$ on glutamate-induced calcium signal shown as a difference in Fura-2 ratio. $(n=67$ cells- in control; $n=56$ cells $(0.5 \mu \mathrm{M}$ TG- $2112 \mathrm{x}) ; n=76$ cells $(1 \mu \mathrm{M}) * * p<0.001$
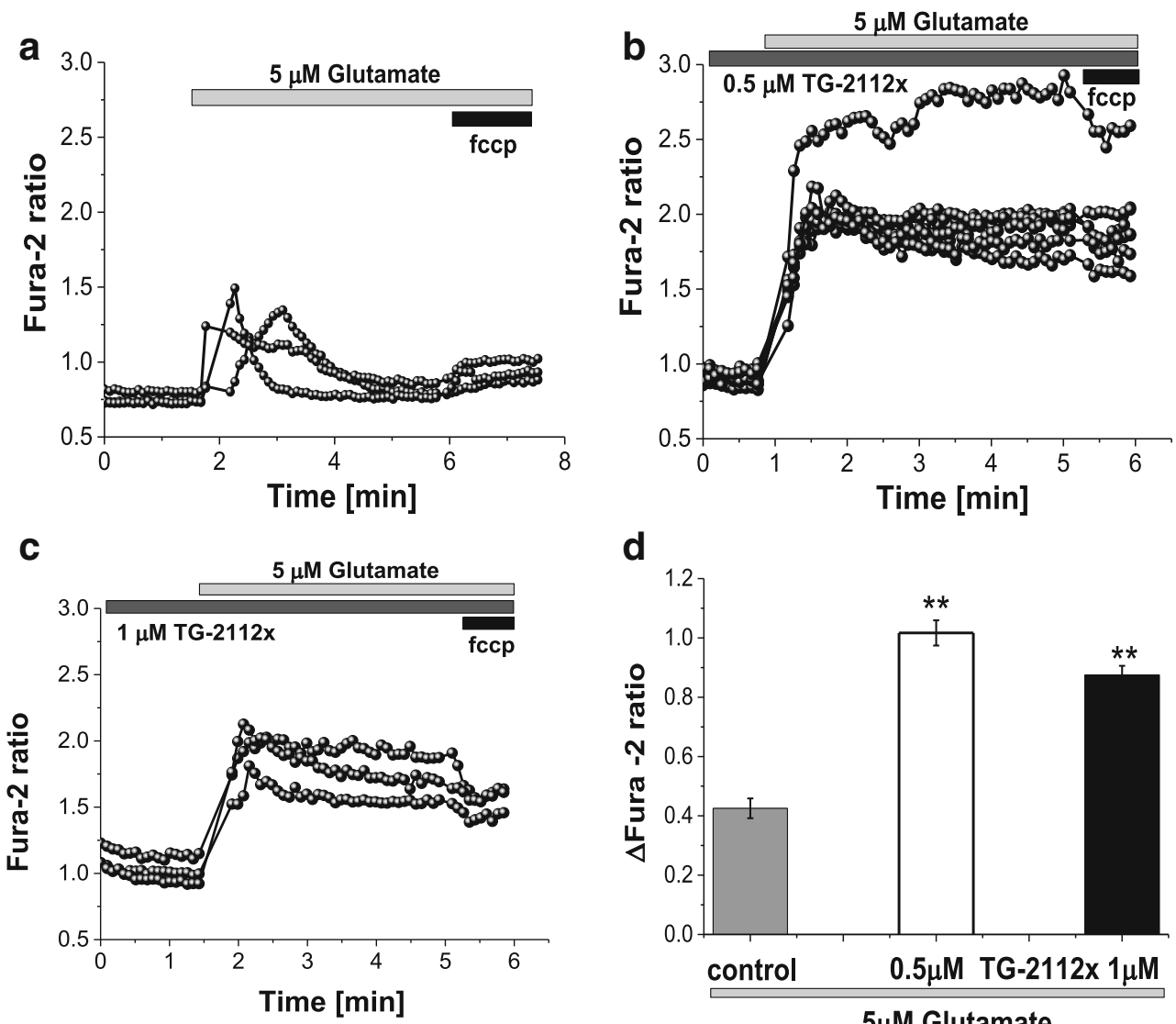

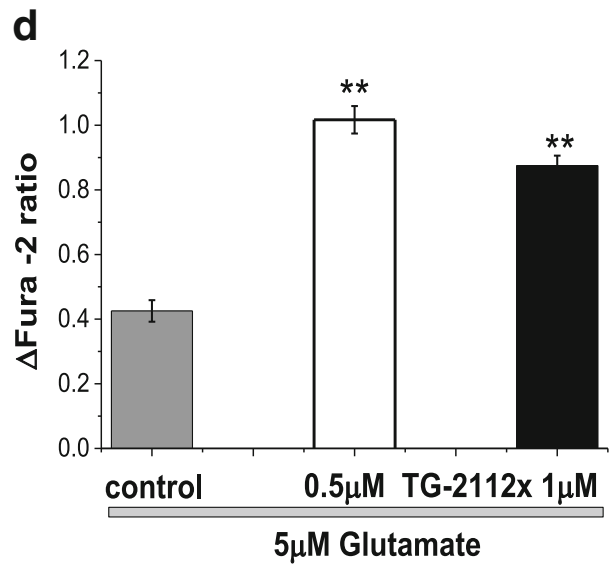

the processi even in the time of delayed calcium deregulation in cell body, and the rise in mitochondrial calcium $\left(\left[\mathrm{Ca}^{2+}\right]_{\mathrm{m}}\right)$ can be easily measured in neuronal dendrites (Fig. 4aii, bii Fig. 5a, b). However, in agreement with the data obtained with fura-ff (Fig. 2a, b), pre-incubation of cortical neurons with TG-2112x (5 min) did not change the effect of $100 \mu \mathrm{M}$ glutamate on $\left[\mathrm{Ca}^{2+}\right]_{\mathrm{c}}$ (Fig. 4ai, bi) but in contrast to control, it suppressed the rise in $\left[\mathrm{Ca}^{2+}\right]_{\mathrm{m}}$ that can be easily detected in the area of the processi (Fig. 4aii, bii; Fig. 5a, b). It should be noted that TG-2112x did not completely block mitochondrial calcium uptake in these cells, but protected against calcium overload. Thus, TG-2112x inhibits mitochondrial calcium uptake in glutamate-stimulated neurons.

Considering all difficulties in separation of the Rhod-5n signal in cytosol and mitochondria, we used genetically encoded indicator for mitochondrial $\mathrm{Ca}^{2+}$ MitoGCaMP6 (Fig. $5 \mathrm{~d}$, dii). Glutamate $(5 \mu \mathrm{M})$ induced oscillation in MitoGCaMP6 fluorescence, which was not observed under resting conditions (Fig. 5d) which can be explained by the nature of mitochondrial uptake in these cells or by some properties of the indicator because it was observed in control and in experiments with inhibitors. Application of the $5 \mu \mathrm{M}$ glutamate to TG-2112x treated neurons $(0.5 \mu \mathrm{M}$ for $20 \mathrm{~min})$ induced significant decrease in mitochondrial calcium uptake (from $237 \pm 29$ arb. $\mathrm{U}$ to $86 \pm 14$ arb $\mathrm{U}, n=26$ cells and 35 cells for vehicle and TG-2112x; $p<0.01)$. Importantly, Tg- 2112x changed also the shape of the signal (Fig. 5d). The effect of the TG-2112x was comparable with the pretreatment of the neurons with Ru360 $(10 \mu \mathrm{M}$ for $20 \mathrm{~min}$, changing the solution with fresh Ru360 to avoid oxidation of the compound; Fig. 5d). Application of $5 \mu \mathrm{M}$ glutamate to neurons incubated with Ru360 significantly but not completely reduce calcium rise in mitochondria (from $237 \pm$ 29 arb. $\mathrm{U}$ in control to $68 \pm 16$ arb. $\mathrm{U}, n=21$ neuron; $p<$ $0.01)$.

\section{TG-2112x Inhibits Calcium-Induced Swelling of Isolated Rat Brain Mitochondria}

In order to identify if TG-2112x has a direct action on mitochondrial calcium uptake, we study the effect of this compound on the calcium-induced mitochondrial swelling.

We found that TG-2112x attenuates the $\mathrm{Ca}^{2+}$-induced swelling of isolated rat brain mitochondria in a concentration-dependent manner with significant inhibition above concentration of $1 \mu \mathrm{M}$ (Fig.6a). However, TG-2112x at concentration of $30 \mu \mathrm{M}$ and above induces mitochondrial swelling without addition of calcium suggesting some membrane modifying effects of this compound at high concentrations. 
Fig. 4 TG-2112x had no effect of the glutamate-induced mitochondrial calcium overload. Glutamate induced delayed calcium deregulation in control (a, aii) and in TG-2112x $(0.5 \mu \mathrm{M}$; b, bii)-treated neurons measured with low affinity calcium indicator Rhod-5n. Effect $100 \mu \mathrm{M}$ on mitochondrial calcium is impossible to detect in cell body due to DCD, but the effect of TG-2112x on glutamateinduced calcium uptake is easily detectable in processi (aii, bii). Traces represent individual cells (measured from cytosolic area ai) or mitochondria (bi). c Summary of the cytosolic responses to glutamate in control $(n=122$ neurons) and treated with TG2112x ( $0.5 \mu \mathrm{M} ; n=99$ neurons $)$
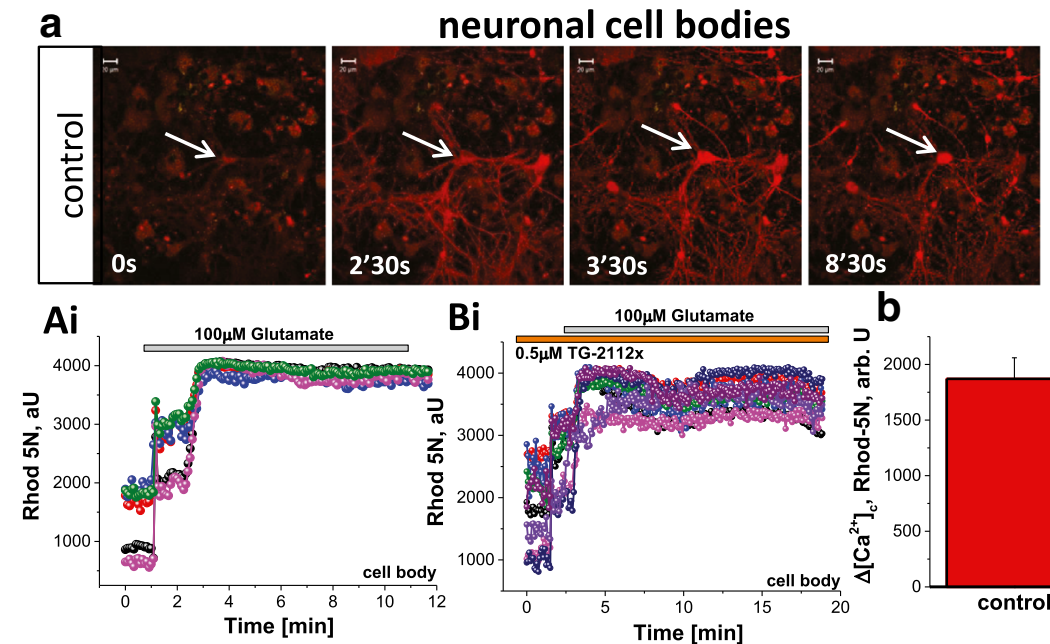

b

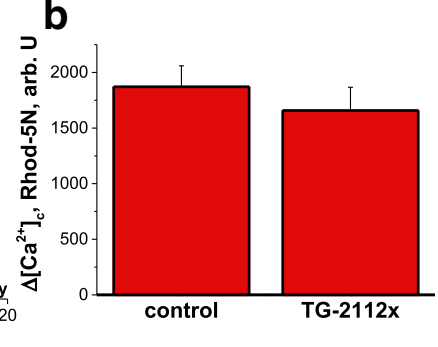

\section{B}
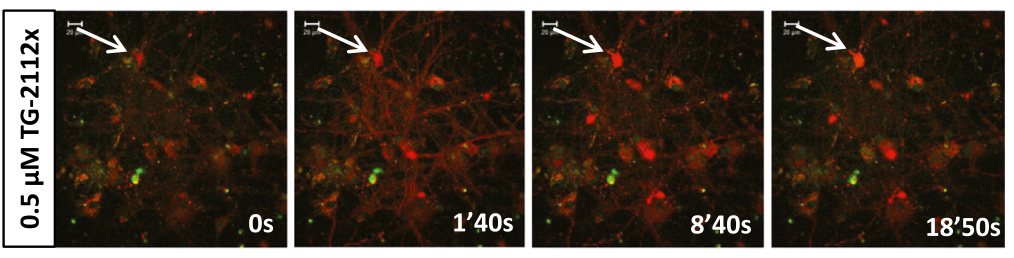

Aii

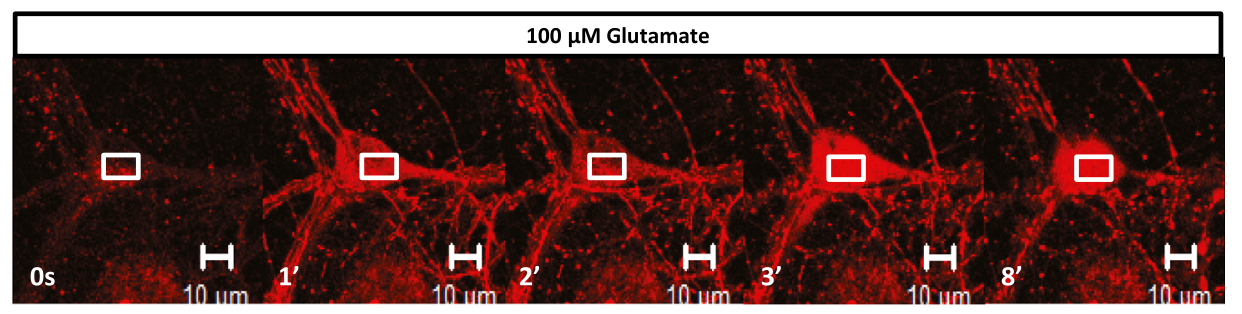

Bii

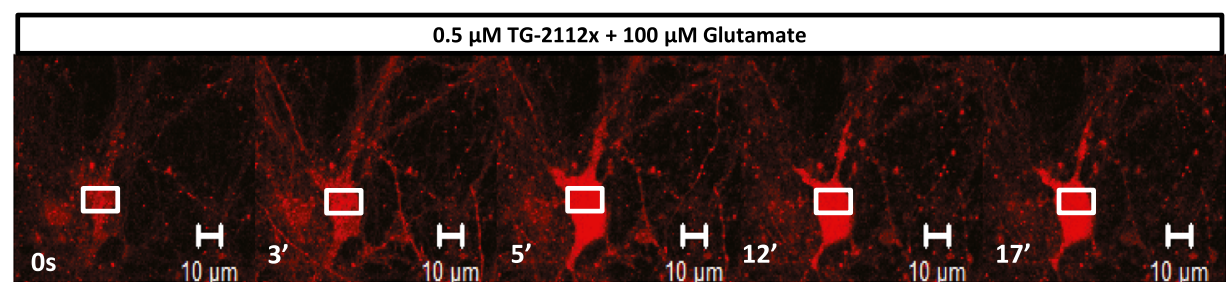

\section{Effect of TG-2112x on Calcium Retention Capacity}

Application of calcium to isolated mitochondria induces mitochondrial $\mathrm{Ca}^{2+}$ uptake and can be blocked by inhibitor of the calcium uniporter - Ru360. Incubation of mitochondria with TG-2112x did not block mitochondrial calcium uptake initiated by application of single or several boluses of $\mathrm{CaCl}_{2}$ ( $8 \mu \mathrm{mol} / \mathrm{mg}$ mitochondrial protein or $1.5 \div 2 \mu \mathrm{M}$ ) and moreover TG-2112x at $100 \mathrm{nM}-10 \mu \mathrm{M}$ increased mitochondrial calcium retention capacity with calcium additions in the "bolus mode" (Fig. 6c), and only at concentration above $5 \mu \mathrm{M}$, the decrease in CRC and the rate of calcium uptake were observed. It should be noted that effects of TG-2112x on mitochondrial calcium uptake were not dependent of the type of mitochondrial substrate used (Fig. 6b, c).

\section{TG-2112x Inhibits Calcium Uptake in Mitochondria of Permeabilized Neurons and Astrocytes}

Another direct way to estimate the effect of TG-2112x on MCU is measurement of $\mathrm{Ca}^{2+}$ uptake in mitochondria of permeabilized cells. These experiments allow to directly measure the kinetics of $\mathrm{Ca}^{2+}$ uptake under application of variety of calcium concentrations in the pseudo-intracellular recording solution [19]. Additions of buffered calcium $(0.5$ and $1 \mu \mathrm{M}$, $n=5$ experiments; Fig. 6d) increased mitochondrial calcium 
Fig. 5 TG-2112x protects neurons against glutamateinduced mitochondrial calcium overload. TG-2112x $(0.5 \mu \mathrm{M})$ blocks the calcium rise in majority of the mitochondria in the neuronal processi (b, bii) compare to control neurons (a, aii). Note that rise in rhod-5n signal in TG-2112x-treated neurons has recovered after an initial peak compared to the control neurons. The traces represent individual mitochondria from the processi. c Summary of the mitochondrial responses to glutamate in control $(n=122$ neurons) and treated with TG$2112 \mathrm{x}(0.5 \mu \mathrm{M} ; n=99)$. ** $p<$ 0.001 . d (representative traces), dii (representative images)effect of $5 \mu \mathrm{M}$ glutamate in control ( $n=26$ neurons), TG2112x-treated cells $(n=35)$ and neurons treated with $10 \mu \mathrm{M}$ Ru360 ( $n=21$ neuron) measured with genetically-encoded indicator for mitochondrial calcium MitoGCaMP6

\section{mixed processi}

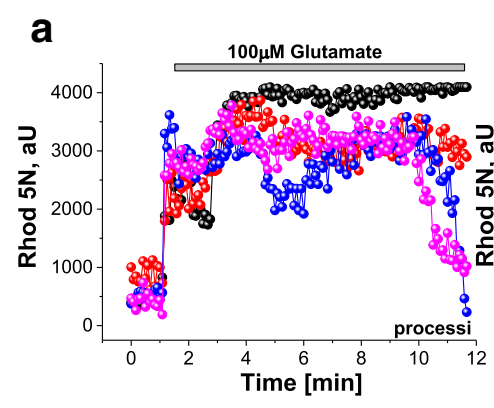

b
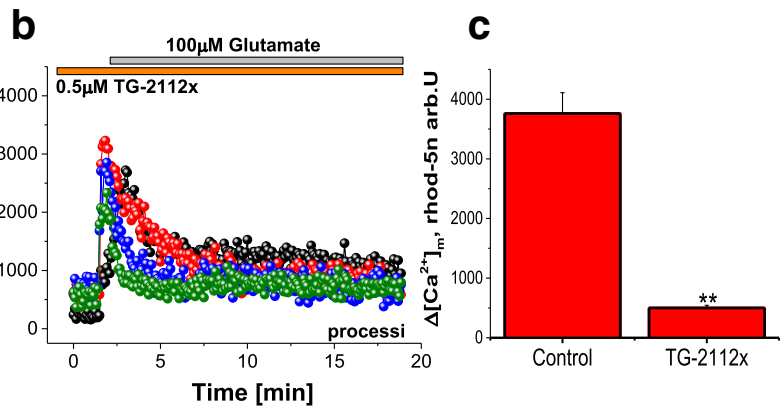

Aii

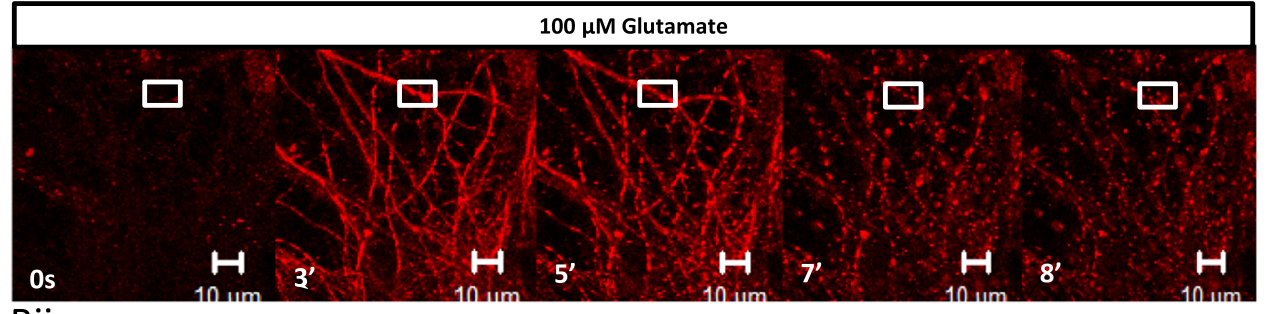

Bii

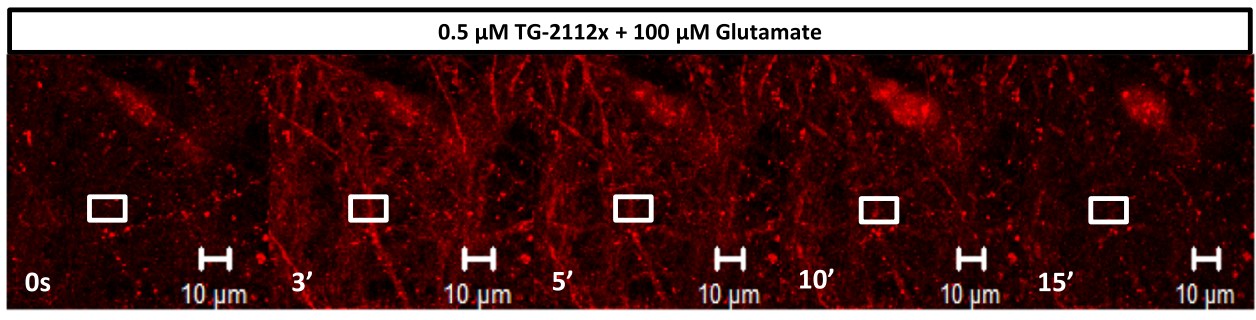

Dii
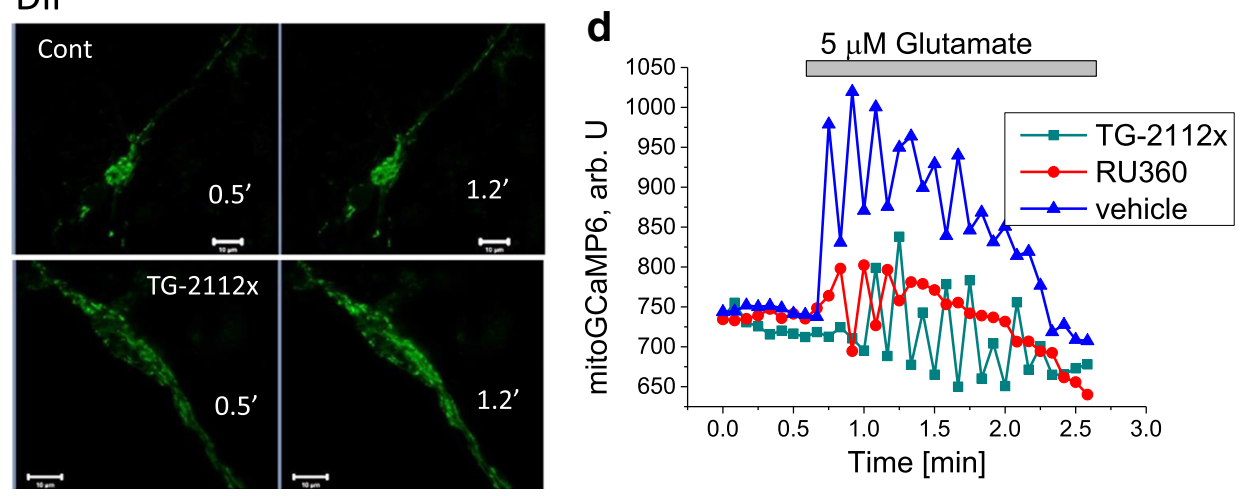

content. Application of the electrogenic calcium ionophore ferutinin $(20 \mu \mathrm{M}$; $[20,21]$ induced further increase in $\left[\mathrm{Ca}^{2+}\right]_{\mathrm{m}}$. Application of the same calcium concentrations to the permeabilized neurons and astrocytes in the presence of TG-2112x ( $0.5 \mu \mathrm{M} ; n=4$ experiments $)$ did not induced any increase in $\left[\mathrm{Ca}^{2+}\right]_{\mathrm{m}}$. Importantly, these mitochondria have been still potent, with maintained $\Delta \psi \mathrm{m}$ that allows electrogenic ionophores to work, and ferutinin induced increase in mitochondrial calcium. Moreover, further application of buffered calcium $(1 \mu \mathrm{M})$ induced increase of $\left[\mathrm{Ca}^{2+}\right]_{m}$ in TG2112x-treated mitochondria (Fig. 6e). Thus, TG-2112x inhibits physiological influx into mitochondria (uniporter) while alternative transport, electrogenic calcium ionophore, is still able to produce increase of $\mathrm{Ca}^{2+}$ in these mitochondria.

\section{TG-2112x Does Not Induce Mitochondrial Dysfunction and Changes in $\Delta \psi m$}

Complete and partial inhibition of mitochondrial calcium uptake could be induced by mitochondrial depolarization [22]. Using Rh123 as an indicator of mitochondrial membrane potential in intact neurons and astrocytes, we found that application of TG-2112x induces slow and progressive decrease (14 $\pm 1 \% ; n=4$ experiments) in Rh123 fluorescence that 
Fig. 6 Effect of TG-2112x on the mitochondrial calcium uptake. TG-2112x inhibits calciuminduced swelling of isolated rat brain mitochondria (a). TG$2112 x$ influence on the calcium retention capacity in isolated rat brain mitochondria with different respiratory substrates (b $5 \mathrm{mM}$ glutamate/malate, c $5 \mathrm{mM}$ succinate with complex I inhibitor $1 \mu \mathrm{M}$ rotenone). Application of $100 \mathrm{nM}-5 \mu \mathrm{M}$ calcium to mitochondria in permeabilized neurons and astrocytes induced rise in $\left[\mathrm{Ca}^{2+}\right]_{\mathrm{m}}$ in control $(\mathbf{d}, n=5$ experiments), but not in TG-

$2112 \mathrm{x}(0.5 \mu \mathrm{M} ; n=4$ experiments)-treated mitochondria (e)
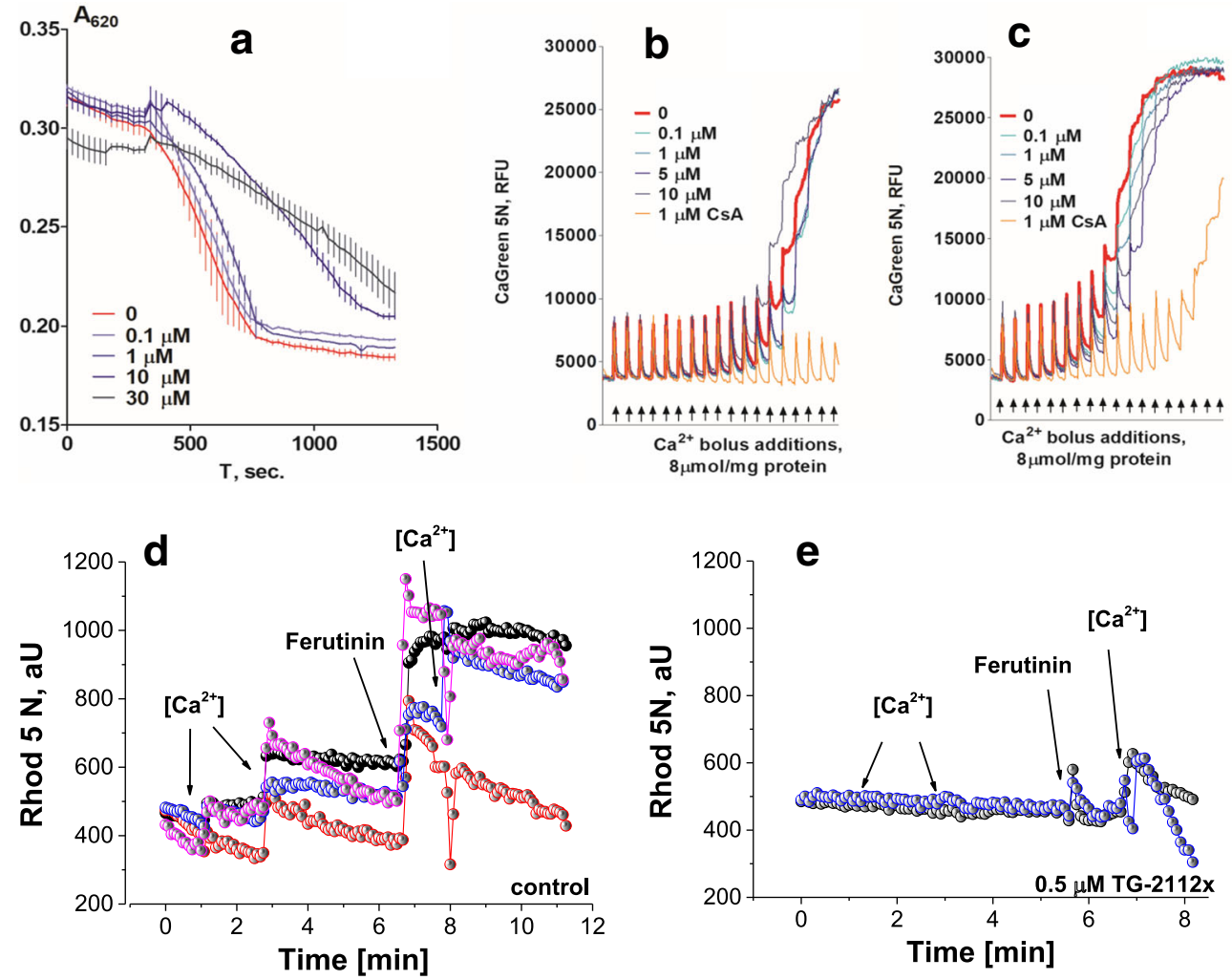

corresponds to an increase of $\Delta \psi \mathrm{m}$ (complete depolarization by $1 \mu \mathrm{M}$ FCCP at the end of the experiment produced the opposite effect on Rh123 fluorescence - Fig. 7a). Thus, the effect of TG-2112x on mitochondrial calcium transport is not due to an effect on $\Delta \psi \mathrm{m}$.

In identifying the effect of the TG-2112x on the cellular bioenergetics, both oxygen consumption rates (OCR) and extracellular acidification rates (ECAR) of co-cultures of cortical neurones and astrocytes were measured in an XF96 extracellular flux analyzer. We have not detected any significant difference between the basal OCR, proton leak, ATP-linked respiration, non-mitochondrial oxygen consumption of control probe, and in the presence of $0.1 \div 10 \mu \mathrm{M}$ of TG-2112x (Fig. 7d). However, a tendency to an increased respiratory capacity (FCCP application) was observed (Fig. 7e). In order to investigate effect of TG-2112x on mitochondrial respiration more specifically, we have measured NADH autofluorescence in co-cultures of primary neurons and astrocytes. Mitochondrial level of NADH is dependent on the activity complex I, and NADH autofluorescence correlates inversely with the respiratory chain activity. In order to identify mitochondrial NADH (which need to be separated from cytosolic $\mathrm{NADH}$ and NADPH autofluorescence), we added FCCP $(1 \mu \mathrm{M})$ to maximize mitochondrial respiration that lead minimal level of NADH in mitochondria (taken as $0 \%$ ), then added $\mathrm{NaCN}(1 \mathrm{mM})$ to inhibit mitochondrial respiration and therefore maximize the mitochondrial NADH $(100 \%)$ (Fig. 7b). We have found that application of TG-2112x activates consumption of NADH in mitochondria that suggests activation of complex I-related respiration (Fig. 7b). Activity of complex II can be assessed by measuring autofluorescence of $\mathrm{FAD}^{++}$considering that $\mathrm{FAD}\left(\mathrm{H}_{2}\right)$ is the complex II substrate. $\mathrm{FAD}^{++}$redox level was estimated after application of FCCP (100\%) and NaCN (taken as 0\%). TG-2112x (0.5$1 \mu \mathrm{M})$ is increased autofluorescence of mitochondrial FAD that suggests activation of the mitochondrial complex IIrelated respiration in intact neurons and astrocytes $(n=5$ experiments; Fig. 7c).

Thus, TG-2112x in concentrations which inhibit mitochondrial calcium uptake, stimulates respiration and increases mitochondrial membrane potential.

\section{TG-2112x Protects Neurons Against Glutamate- and Ionomycin-Induced Cell Death}

We then examined the effect of 15-min exposure of cultures to $100 \mu \mathrm{M}$ glutamate on cell viability (estimated after $24 \mathrm{~h}$ ) and found that remarkably, $60.9 \pm 2.03 \%$ of neurons died in this period (Fig. 8a, $n=4$ experiments). Pre-incubation with $0.5 \mu \mathrm{M}$ TG-2112x reduced cell death of cortical neurons to $25 \pm 2.6 \%, p<0.001 ; n=4$ experiments; Fig. 8a). Thus, suppression of mitochondrial calcium uptake by TG-2112x protects neurons against mitochondrial depolarization and cell death. Importantly, TG-2112x was protective not specifically against glutamate excitotoxicity but against calcium-induced cell death. Thus, treatment of primary culture of cerebellar 
Fig. 7 TG-2112x does not induce mitochondrial dysfunction. TG-

2112x induced mild

hyperpolarization of

mitochondria (resulted in a

decrease of Rh123 fluorescence;

a; $n=4$ experiments), decrease of

mitochondrial NADH

autofluorescence (b; $n=4$

experiments), and increase in

FAD++ fluorescence (c; $n=5$

experiments) shown as

representative traces from the single cells. TG-2112x did not influence the basal oxygen consumption rate (OCR), nonmitochondrial respiration of mixed cultures of cortical neurones, and glial cells (d lines represents the mean value traces of different experiments). OM oligomycin $(3 \mu \mathrm{M})$, FCCP $(3 \mu \mathrm{M}), \mathrm{AA} /$ Rot rotenone $(1 \mu \mathrm{M})$ with antimycin $(1 \mu \mathrm{M})$, but a tendency to an increased respiratory capacity in the presence of the mitochondrial uncoupler FCCP was observed (e; $n=5$ of each experiments)
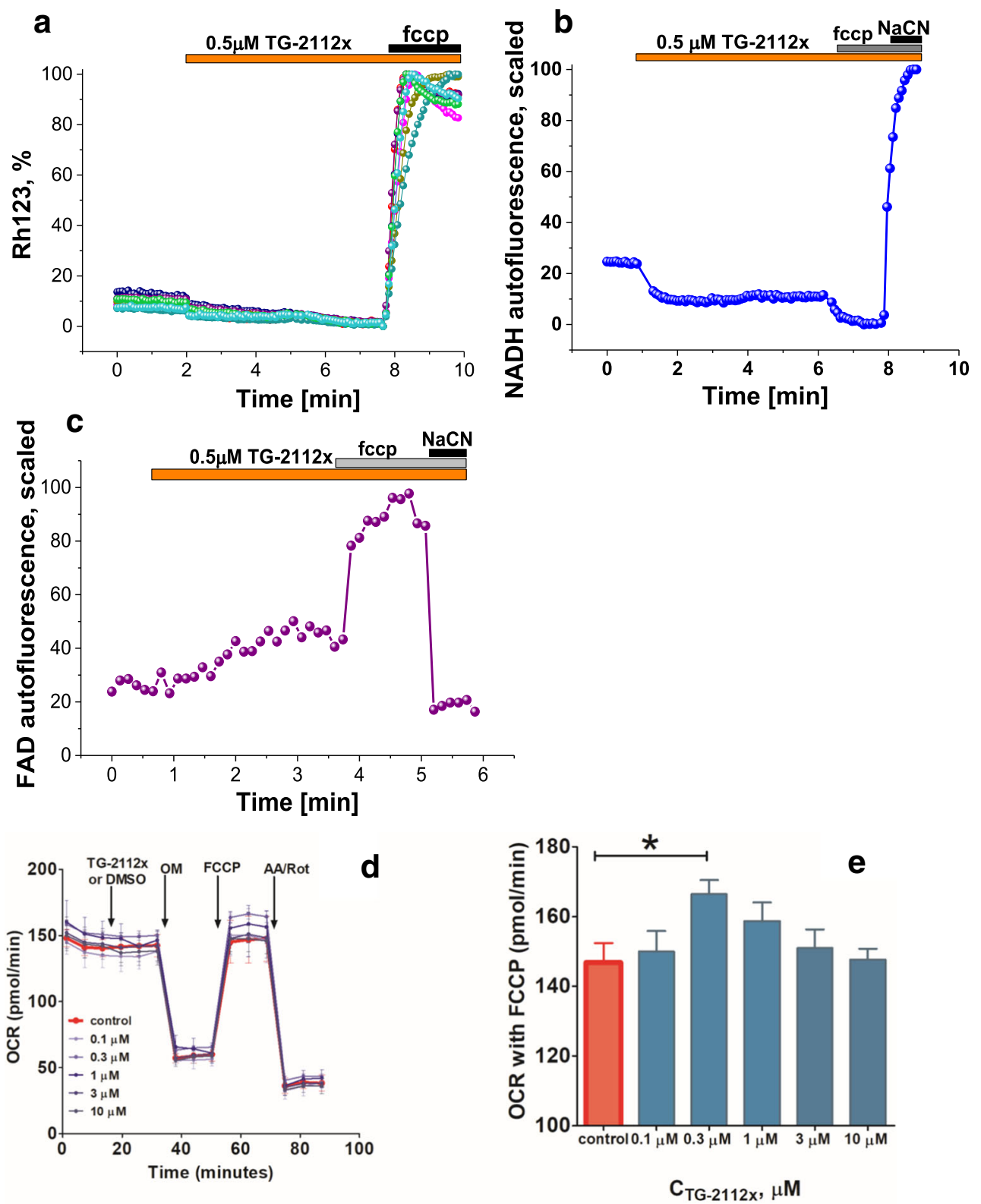

granular cells with $3 \mu \mathrm{M}$ ionomycin for $24 \mathrm{~h}$ induced cell death in $\sim 50 \%$ cells (Fig. 8 b). Pre-treatment of the cells with TG-2112x significantly protected them from glutamateinduced cell death, yielding maximal effect at concentrations of 1 and $3 \mu \mathrm{M}$.

\section{Discussion}

The data from experiments described here suggest that (a) our novel compound TG-2112x protects neurons against neuronal cell death induced by toxic concentrations of glutamate; (b) the protective effect is not based on the inhibition of glutamate receptors - neurons exhibited similar to control delayed calcium deregulation; (c) TG-2112x blocked glutamate-induced mitochondrial depolarization in majority of the cells; and (d) the effect of TG-2112x on mitochondrial membrane potential and neuronal cell survival can be explained by the sequestration of the mitochondrial calcium that inhibits (more likely by blocking of low concentration calcium uptake) mitochondrial calcium overload.

The synchrony of mitochondrial depolarization and the calcium deregulation has suggested that these two processes must be interdependent and both essential in the mechanism of glutamate-induced cell death [23-25]. Here, we show that despite that first stage of mitochondrial depolarization is not linked to opening of mitochondrial permeability transition pore and trigger of cell death $[5,26]$; the loss of $\Delta \psi \mathrm{m}$ is essential point in the mechanism of cell death. Delayed calcium deregulation for long time was associated as an initial 

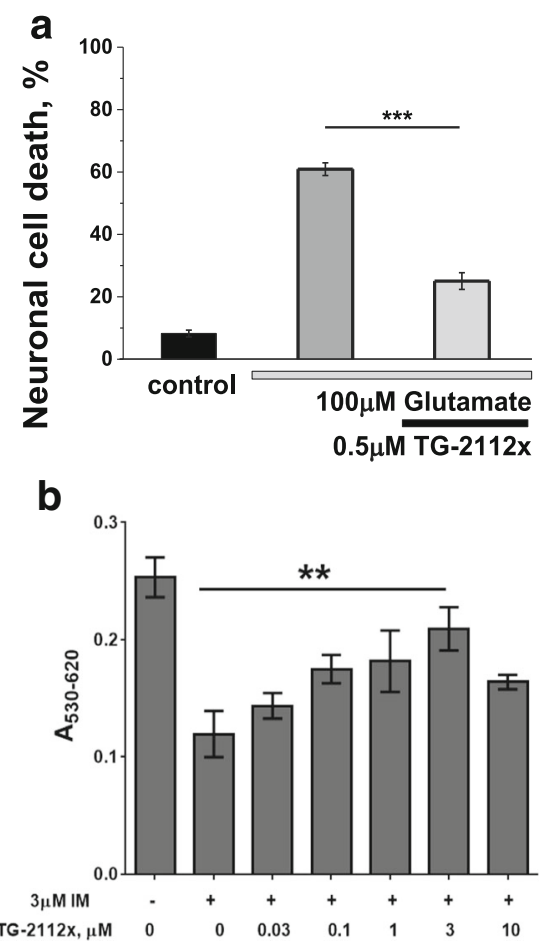

Fig. 8 TG-2112x protects neurons against calcium-induced cell death. Pre-incubation of the cortical neurons with $0.5 \mu \mathrm{M}$ TG2112x protects cells against cell death, induced by $100 \mu \mathrm{M}$ glutamate (a). TG-2112x dose-dependently protects cerebellar granular cells against ionomycininduced neuronal death (b), $n=4$ of each experiments; $* * p<0.001$; $* * * p<0.0001$

point of the neuronal loss under glutamate exposure [27]. Here, we found that neurons could survive even after prolonged delayed calcium deregulation if their mitochondria are not depolarized. Although mitochondrial calcium uptake has been suggested as initial step in glutamate excitotoxicity [18] and mitochondrial calcium uptake was linked to mitochondrial depolarization [5], the direct protection of the neurons against high doses of glutamate by inhibition of mitochondrial calcium uptake is shown here.

There are number of ways to protect neurons against excitotoxicity - inhibition of the NMDA receptors, by stimulation of active calcium transport $\left(\mathrm{Ca}^{2+}\right.$ ATPases) or by limitation of the NMDA receptors activation by neuromodulators $[13,28,29]$. Unfortunately, these strategies are limited by inhibition of the important physiological functions in the neurons under normal conditions. Sequestration, but not full inhibition of mitochondrial calcium uptake by TG-2112x, could be beneficial in the number of diseases with calcium-induced pathology including stroke, Alzheimer's disease, and epilepsy $[16,30,31]$. Considering the modification of calcium signaling by alpha-synuclein [32] and inhibition of mitochondrial calcium efflux in mitochondria of neurons with familial forms of Parkinson's disease, limitation of calcium uptake by TG2112x would be also cell protective [33-35].
Application of TG-2112x in our experiments allow us to point one of the important questions in basic calcium studies, i.e., molecular inhibition of MCU has no effect on low concentration calcium uptake [36]. Effect of TG-2112x on mitochondrial calcium uptake which we observed here could be induced not by inhibition of MCU but exclusively on the system of low calcium uptake. This low concentration calcium uptake is very important considering the fact that concentration of $\mathrm{Ca}^{2+}$ in cytosol in physiology usually does not exceed $1 \mu \mathrm{M}$ and under conditions of pathology (such as glutamate excitotoxicity) reaches 5-7 $\mu \mathrm{M}$ that is much lower than the threshold for MCU [18]. Protective properties of TG-2112x strongly suggest an important role of low concentration mitochondrial calcium uptake in physiology and pathology.

The mechanism of the low concentration calcium uptake could be solely dependent on one transporter or can have a multiple players. Thus, we cannot exclude the action of MCU in high affinity mode which is not affected by Ru360. However, this is a less likely mechanism considering low calcium uptake in MCU deficiency [35]. We also can exclude possible effect of TG-2112x on calcium precipitation with phosphate in mitochondria because this process requires higher $\mathrm{Ca}^{2+}$ concentration [37]. The number of the natural compounds could play the role of mitochondrial calcium ionophore [38,39] such as prostaglandin [40], polyhydroxybutyrate, or polyphosphate $[41,42]$ and many others. We cannot exclude effect of TG-2112x on biochemical pathways which produce these potential modulators of mitochondrial calcium uptake.

Funding Information Synthesis and primary study of the agent TG2112x was supported by RSF grant no. 14-23-00160P, and study of influence on bioenergetics of brain cells was supported by Russian State assignment No. 0090-2017-0019. We also thank for the support from the Department of Health's NIHR Biomedical Research Centre's funding streams.

\section{Compliance with Ethical Standards}

Conflict of Interest The authors declare that they have no conflict of interest.

Open Access This article is distributed under the terms of the Creative Commons Attribution 4.0 International License (http:// creativecommons.org/licenses/by/4.0/), which permits unrestricted use, distribution, and reproduction in any medium, provided you give appropriate credit to the original author(s) and the source, provide a link to the Creative Commons license, and indicate if changes were made.

\section{References}

1. Choi DW (1992) Excitotoxic cell death. J Neurobiol 23:1261-1276

2. McConeghy KW, Hatton J, Hughes L, Cook AM (2012) A review of neuroprotection pharmacology and therapies in patients with acute traumatic brain injury. CNS Drugs 26:613-636

3. Pivovarova NB, Andrews SB (2010) Calcium-dependent mitochondrial function and dysfunction in neurons. FEBS J 277:3622-3636 
4. Vergun O, Keelan J, Khodorov BI, Duchen MR (1999) Glutamateinduced mitochondrial depolarisation and perturbation of calcium homeostasis in cultured rat hippocampal neurones. J Physiol 519(Pt 2): $451-466$

5. Abramov AY, Duchen MR (2008) Mechanisms underlying the loss of mitochondrial membrane potential in glutamate excitotoxicity. Biochim Biophys Acta 1777:953-964

6. Mammucari C, Raffaello A, Vecellio RD, Rizzuto R (2016) Molecular structure and pathophysiological roles of the mitochondrial calcium uniporter. Biochim Biophys Acta 1863:2457-2464

7. Qiu J, Tan YW, Hagenston AM, Martel MA, Kneisel N, Skehel PA, Wyllie DJA, Bading H et al (2013) Mitochondrial calcium uniporter Mcu controls excitotoxicity and is transcriptionally repressed by neuroprotective nuclear calcium signals. Nat Commun 4:2034

8. Abeti R, Parkinson MH, Hargreaves IP, Angelova PR, Sandi C, Pook MA, Giunti P, Abramov AY (2016) Mitochondrial energy imbalance and lipid peroxidation cause cell death in Friedreich's ataxia. Cell Death Dis 7:e2237

9. Khodorov B, Pinelis V, Storozhevykh T, Yuravichus A, Khaspekhov L (1999) Blockade of mitochondrial Ca2+ uptake by mitochondrial inhibitors amplifies the glutamate-induced calcium response in cultured cerebellar granule cells. FEBS Lett 458:162-166

10. Jekabsons MB, Nicholls DG (2004) In situ respiration and bioenergetic status of mitochondria in primary cerebellar granule neuronal cultures exposed continuously to glutamate. J Biol Chem 279: 32989-33000

11. Abramov AY, Duchen MR (2010) Impaired mitochondrial bioenergetics determines glutamate-induced delayed calcium deregulation in neurons. Biochim Biophys Acta 1800:297-304

12. Domijan AM, Kovac S, Abramov AY (2012) Impact of fumonisin B1 on glutamate toxicity and low magnesium-induced seizure activity in neuronal primary culture. Neuroscience 202:10-16

13. Vaarmann A, Kovac S, Holmstrom KM, Gandhi S, Abramov AY (2013) Dopamine protects neurons against glutamate-induced excitotoxicity. Cell Death Dis 4:e455

14. Domijan AM, Abramov AY (2011) Fumonisin B1 inhibits mitochondrial respiration and deregulates calcium homeostasis - implication to mechanism of cell toxicity. Int J Biochem Cell Biol 43:897-904

15. Shevtsova EF, Vinogradova DV, Kireeva EG, Reddy VP, Aliev G, Bachurin SO (2014) Dimebon attenuates the Abeta-induced mitochondrial permeabilization. Curr Alzheimer Res 11:422-429

16. Bachurin SO, Shevtsova EF, Makhaeva GF, Grigoriev VV, Boltneva NP, Kovaleva NV, Lushchekina SV, Shevtsov PN et al (2017) Novel conjugates of aminoadamantanes with carbazole derivatives as potential multitarget agents for $\mathrm{AD}$ treatment. Sci Rep 7:45627

17. Stout AK, Reynolds IJ (1999) High-affinity calcium indicators underestimate increases in intracellular calcium concentrations associated with excitotoxic glutamate stimulations. Neuroscience 89:91-100

18. Stout AK, Raphael HM, Kanterewicz BI, Klann E, Reynolds IJ (1998) Glutamate-induced neuron death requires mitochondrial calcium uptake. Nat Neurosci 1:366-373

19. Abramov AY, Duchen MR (2011) Measurements of threshold of mitochondrial permeability transition pore opening in intact and permeabilized cells by flash photolysis of caged calcium. Methods Mol Biol 793:299-309

20. Zamaraeva MV, Hagelgans AI, Abramov AY, Ternovsky VI, Merzlyak PG, Tashmukhamedov BA, Saldkhodzjaev AI (1997) Ionophoretic properties of ferutinin. Cell Calcium 22:235-241

21. Abramov AY, Duchen MR (2003) Actions of ionomycin, 4BrA23187 and a novel electrogenic Ca2+ ionophore on mitochondria in intact cells. Cell Calcium 33:101-112

22. Abeti R, Abramov AY (2015) Mitochondrial $\mathrm{Ca}(2+)$ in neurodegenerative disorders. Pharmacol Res 99:377-381

23. Duchen MR (2000) Mitochondria and $\mathrm{Ca}(2+)$ in cell physiology and pathophysiology. Cell Calcium 28:339-348
24. Khodorov BI, Storozhevykh TP, Surin AM, Yuryavichyus AI, Sorokina EG, Borodin AV, Vinskaya NP, Khaspekov LG et al (2002) The leading role of mitochondrial depolarization in the mechanism of glutamate-induced disruptions in $\mathrm{Ca} 2+$ homeostasis. Neurosci Behav Physiol 32:541-547

25. Keelan J, Vergun O, Duchen MR (1999) Excitotoxic mitochondrial depolarisation requires both calcium and nitric oxide in rat hippocampal neurons. J Physiol 520(Pt 3):797-813

26. Surin AM, Gorbacheva LR, Savinkova IG, Sharipov RR, Khodorov BI, Pinelis VG (2014) Study on ATP concentration changes in cytosol of individual cultured neurons during glutamate-induced deregulation of calcium homeostasis. Biochemistry (Mosc) 79:146-157

27. Randall RD, Thayer SA (1992) Glutamate-induced calcium transient triggers delayed calcium overload and neurotoxicity in rat hippocampal neurons. J Neurosci 12:1882-1895

28. Zhao JJ, Gao S, Jing JZ, Zhu MY, Zhou C, Chai Z (2014) Increased $\mathrm{Na}+\mathrm{Ca} 2+$ exchanger activity promotes resistance to excitotoxicity in cortical neurons of the ground squirrel (a hibernator). PLoS One 9:e113594

29. Suwanjang W, Holmstrom KM, Chetsawang B, Abramov AY (2013) Glucocorticoids reduce intracellular calcium concentration and protects neurons against glutamate toxicity. Cell Calcium 53: 256-263

30. Kovac S, Domijan AM, Walker MC, Abramov AY (2012) Prolonged seizure activity impairs mitochondrial bioenergetics and induces cell death. J Cell Sci 125:1796-1806

31. Angelova PR, Abramov AY (2017) Alpha-synuclein and betaamyloid - different targets, same players: calcium, free radicals and mitochondria in the mechanism of neurodegeneration. Biochem Biophys Res Commun 483:1110-1115

32. Angelova PR, Ludtmann MH, Horrocks MH, Negoda A, Cremades $\mathrm{N}$, Klenerman D et al (2016) Ca2+ is a key factor in alphasynuclein-induced neurotoxicity. J Cell Sci 129:1792-1801

33. Ludtmann MHR, Abramov AY (2018) Mitochondrial calcium imbalance in Parkinson's disease. Neurosci Lett 663:86-90

34. Kostic M, Ludtmann MH, Bading H, Hershfinkel M, Steer E, Chu CT et al (2015) PKA phosphorylation of NCLX reverses mitochondrial calcium overload and depolarization, promoting survival of PINK1-deficient dopaminergic neurons. Cell Rep 13:376-386

35. Gandhi S, Wood-Kaczmar A, Yao Z, Plun-Favreau H, Deas E, Klupsch K, Downward J, Latchman DS et al (2009) PINK1associated Parkinson's disease is caused by neuronal vulnerability to calcium-induced cell death. Mol Cell 33:627-638

36. Holmstrom KM, Pan X, Liu JC, Menazza S, Liu J, Nguyen TT et al (2015) Assessment of cardiac function in mice lacking the mitochondrial calcium uniporter. J Mol Cell Cardiol 85:178-182

37. Nicholls DG, Chalmers S (2004) The integration of mitochondrial calcium transport and storage. J Bioenerg Biomembr 36:277-281

38. Makhmudova EM, Gagel'gans AI, Mirkhodzhaev UZ, Tashmukhamedov BA (1975) Effect of the mitochondrial ionophore for divalent cations on bilayer phospholipid membranes. Biofizika 20:225-227

39. Blondin GA (1974) Isolation of a divalent cation ionophore from beef heart mitochondria. Biochem Biophys Res Commun 56:97105

40. Kirtland SJ, Baum H (1972) Prostaglandin E 1 may act as a "calcium ionophore". Nat New Biol 236:47-49

41. Smithen M, Elustondo PA, Winkfein R, Zakharian E, Abramov AY, Pavlov E (2013) Role of polyhydroxybutyrate in mitochondrial calcium uptake. Cell Calcium 54:86-94

42. Baev AY, Negoda A, Abramov AY (2017) Modulation of mitochondrial ion transport by inorganic polyphosphate - essential role in mitochondrial permeability transition pore. J Bioenerg Biomembr 49:49-55 